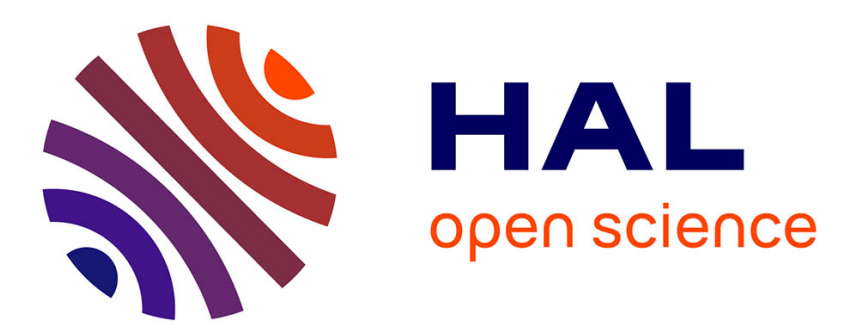

\title{
Pairing GIS and distributed hydrological models using Matlab 2
}

Sleimane Hariri, Sylvain Weill, Jens Gustedt, Isabelle Charpentier

\section{To cite this version:}

Sleimane Hariri, Sylvain Weill, Jens Gustedt, Isabelle Charpentier. Pairing GIS and distributed hydrological models using Matlab 2. CAJG - 2nd Conference of the Arabian Journal of Geosiences, Nov 2019, Sousse, Tunisia. hal-02333260

\section{HAL Id: hal-02333260 https://hal.science/hal-02333260}

Submitted on 25 Oct 2019

HAL is a multi-disciplinary open access archive for the deposit and dissemination of scientific research documents, whether they are published or not. The documents may come from teaching and research institutions in France or abroad, or from public or private research centers.
L'archive ouverte pluridisciplinaire HAL, est destinée au dépôt et à la diffusion de documents scientifiques de niveau recherche, publiés ou non, émanant des établissements d'enseignement et de recherche français ou étrangers, des laboratoires publics ou privés. 


\title{
Pairing GIS and distributed hydrological models using Matlab
}

\author{
Sleimane Hariri ${ }^{1}$, Sylvain Weill ${ }^{2}$, Jens Gustedt ${ }^{1,3}$, Isabelle Charpentier ${ }^{1}$ \\ ${ }^{1}$ ICube UMR 7357, Université de Strasbourg\&CNRS, 67412 Illkirch, France \\ ${ }^{2}$ LHyGeS UMR 7517, Université de Strasbourg\&CNRS, 67000 Strasbourg, France \\ ${ }^{3}$ INRIA, France \\ shariridunistra.fr
}

\begin{abstract}
Observed data are required to carry out hydrological simulations in a watershed for use by policy makers. Hydrological simulations thus require a large interdisciplinary knowledge about modeling, computer sciences, databases, GIS. A Matlab preprocess prior to the hydrological modeling is presented for educational purposes and an easy uptake by non-GIS users. Moreover, this allows for parallel computing. This pre-process builds on two renowned and freely available Matlab toolboxes providing GIS and mesh functionalities. Additional functionalities allow for a decomposition of watersheds with respect to parameterized constraints, including the meshing of the subdomains and the construction of an oriented flow graph. The method is exemplified on a subbasin of the Saar River.
\end{abstract}

Keywords: Hydrology, Domain decomposition method, GIS modelling.

\section{Introduction}

Data - topography, climate, land cover, soil properties - are required to carry out hydrological simulations in a watershed for use by policy makers. These data are of different nature and usually provided with their own standard data format. Topography and land cover are freely available from national agencies or transnational projects like Copernicus or CORINE Land Cover. Climate data are scarcer in both time and resolution. Fortunately, simulations can be performed using reanalyzes [1]. Soil and geology parameters are usually unknowns and calibrated using climate data, discharge data and hydrological models.

Digital Elevation Models (DEM) store projected topographic information in a gridded format and constitute fundamental data to hydrological studies [2]. Spatial heterogeneities can be accounted by mean of a decomposition of the watershed into smaller geographical units. Conceptual models preferably deal with sub-watersheds to facilitate routing. River analyses are carried out using a one- or two-dimensional partial differential model discretized by meshing the major bed and splitting it longitudi- 
nally. Watershed simulations, surface and underground flows, involve more complex meshes and numerical methods. Domain decomposition has another major advantage since it offers the opportunity to run simulations on a parallel platform.

Only basic interdisciplinary knowledge in GIS, hydrology or computer sciences is usually insufficient to carry out numerical simulations because pairing GIS tools, database and computer models is not an easy task. QGIS and GMSH are loosely interfaced by means of Python and shapefiles read/write. The Python-based open-source framework PIHMgis [3] goes one step further by managing the coupling of GIS tools, data and distributed hydrological modeling through pre- and post-processes. Although a user interface exists and the program code is available, further developments require a good knowledge of GIS tools, Python, and the programming language of the hydrological model under study.

To overcome this shortfall, Matlab is chosen as a framework for pairing GIS and parallel/distributed hydrological models. Thereby, it enable to take advantage of existing toolboxes $[4,5]$. This short paper presents a pre-processor written in Matlab that allows for the management of DEMs with regards to hydrological structures, hydrological modeling and parallel computing.

\section{Methods}

The approach is to propose a user-friendly upgradeable open-source interface implemented in a classical language in sciences and educational communities. Matlab meets these requirements and, additionally, it provides visualization functionalities. A number of free toolboxes, namely TopoToolbox [4] and mSim[5], offer particular GIS operations and mesh generation (through GMSH), respectively. Working in a nonGIS scientific computing framework rather than in a GIS or Python environment may facilitate the uptake by engineering students.

The pre-process workflow ranges from the DEM read to watershed decomposition and sub-mesh generation, carried out with respect to user's constraints.

\subsection{Domain decomposition}

The watershed decomposition can be organized such that it fulfills parameterized user-defined constraints:

1. the account for important hydrological structures (dams/ponds/discharge station) or bridges that can create logjams. are "primary checkpoints";

2. the partition of the domain into more sub-watersheds by placing "secondary checkpoints" on the stream;

3. the design of sub-watersheds with similar areas, typically a few $\mathrm{km}^{2}$. The interest is threefold: ( $i$ ) assigning homogeneous data (soil and climate) at the subwatershed level to account for spatio-temporal variability, (ii) dealing with hydro- 
logical sub-models of similar size, (iii) balancing the computational load on a parallel platform.

All these checkpoints are inlets or outlets of the sub-watershed they delineate. At surface level, these flow interfaces are located on the stream. Domain decomposition functionalities are implemented by building on [4, 5] and Matlab.

\subsection{Preprocess workflow}

A graphical user interface (not shown here) articulates GIS and meshing operations as follows: (1) read the DEM [4], (2a) define user outlets as suggested by the first constraint, (2b) automatically insert additional outlets to satisfy the third constraint, (3) partition the watershed by delineating drainage basins with respect to these outlets [4], (4) format the partition as a shapefile for plotting purposes (shapewrite and shaperead of the "mapping Matlab toolbox"), (5) mesh the subdomains [5], (6) determine inlet and outlet faces, (7) order subdomains to build an upstream to downstream graph. The files generated (sub-domain mesh and oriented flow graph) are used as input file for the hydrological model.

\section{Results}

For the sake of clarity in the figures, the small watershed $\left(89 \mathrm{~km}^{2}\right)$ of the Mutterbach stream near to the city of Sarralbe (Région Grand-Est, France) is used. To serve as a defense waterline in 1940, 6 ponds and 5 dams were built to supply water and to control the floods in the valley. These constitute a set of 11 primary checkpoints allowing for water management. In Figure 1.b, the decomposition is carried out with respect to these hydrological structures (marked with red squares). To anticipate parallel computing, secondary checkpoints have been added to fulfill the third constraint. Figure 1.c displays a decomposition into 58 subdomains, the areas of which range from $1 \mathrm{~km}^{2}$ to $2.5 \mathrm{~km}^{2}$ with an average value of $1.54 \mathrm{~km}^{2}$. The numbers of nodes/elements in the sub-meshes are equal to $1260 / 2200$ on average, respectively.

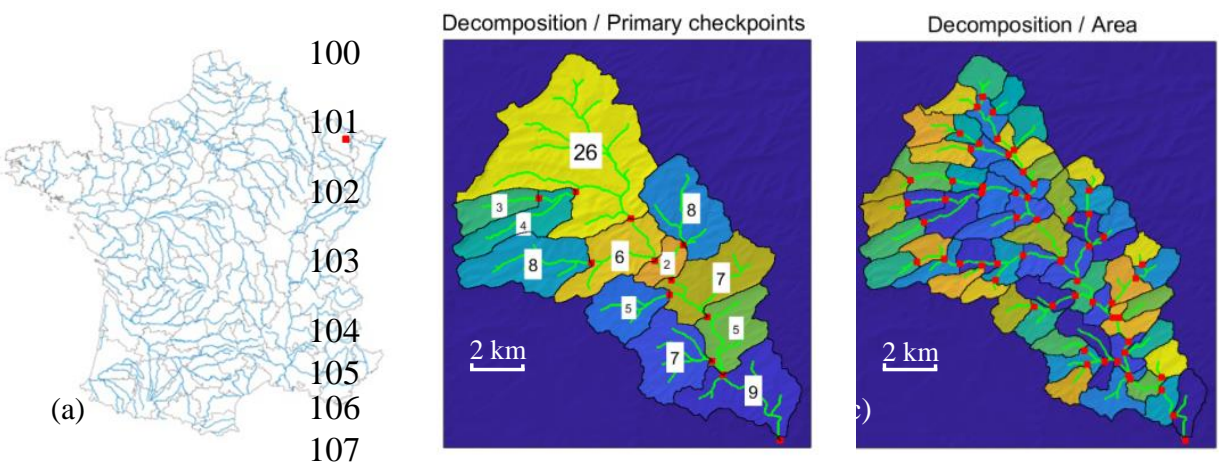

Fig. 1. (a): Location in France (red point); (b): Decomposition/checkpoints; (b) Loadbalanced refined decomposition. 
1104 Discussion

111 Hydrological simulations require a large interdisciplinary knowledge about modeling, 112 computer sciences, databases, GIS... For educational purposes and an easy uptake by 113 non-GIS users, our interdisciplinary team (hydrologists, computer scientists and 114 mathematicians) work on Matlab pre- and post-processes to the hydrological model115 ing. These build on two renowned and freely available Matlab toolboxes [4,5] provid116 ing GIS and mesh functionalities, respectively. Note that both were designed in a 117 hydrological context and come with user guides.

118 For the sake of reproducibility, proposed domain decomposition functionalities 119 (parameterized constraints, watershed decomposition and oriented flow graph) will be 120 exhaustively described and documented in a future work. Then, Matlab codes will be made freely available to serve as a basis to implement other decomposition constraints. Complementary tests were performed on the Saar watershed partly located in France and Germany.

This hydrology-targeted Matlab-GIS framework is intended to be useful not only for education purposes or for a first contact with GIS tools for hydrology modeling, but also as a common basis for interdisciplinary studies with non GIS users. Moreover, it benefits from the numerous toolboxes already developed in and for Matlab.

\section{Conclusion}

129 The Matlab-GIS interface builds on two renowned and freely available Matlab 130 toolboxes providing GIS and mesh functionalities. It has been designed for an easy 131 uptake by non-GIS users and modelers in hydrology. Resulting watershed decomposi132 tion can be interfaced with a conceptual model or with a parallelized finite element model for watershed simulations by using the oriented flow graph for routing.

\section{References}

1. Caillouet, L., Vidal, J.-P., Sauquet, E., Graff, B., Soubeyroux, J.-M: SCOPE Climate: a 142-year daily high-resolution ensemble meteorological. reconstruction dataset over France. Earth System Science Data 11(1), 241-260 (2019).

2. McDonnell, R.A.: Including the spatial dimension: Using Geographical Information Systems in hydrology. Progress in Physical 20(2), 159-177 (1996).

3. Bhatt, G., Kumar, M., Duffy, C.J.: A tightly coupled GIS and distributed hydrologic modeling framework. Environmental Modelling \& Software 62(), 70-84(2014).

4. Schwanghart, W., Kuhn, N.J.: TopoToolbox: A set of Matlab functions for topographic analysis. Environmental Modelling \& Software 25(6), 770-781(2010).

5. Kourakos, G., Harter, T.: Vectorized simulation of groundwater flow and streamline transport. Environmental Modelling \& Software 52, 207-221 (2014). 